\title{
Traditional and innovative methods teaching in English language
}

\author{
G'. Xudoyberganov' ${ }^{1}$, M.Xudoyberganova ${ }^{2}$ \\ ${ }^{1,2}$ The teachers of English language, Tashkent Institute of Irrigation and Agricultural \\ Mechanization Engineers, Uzbekistan \\ Email:xudoyberganov_g@umail.uz
}

\begin{abstract}
Article is about traditional and innovative methods teaching for foreign languages, challenge for any teacher is capturing each student's attention, and conveying ideas effectively enough to create a lasting impression.
\end{abstract}

Keywords: methods, traditional method, creative teaching, grammar-translation method, direct method, ALM method, interactive methods.

\section{INTRODUCTION}

In recent years English has become a universal business language. As first President Islam Karimov stated "Today the world demands that we should say our word, demonstrate our intellectual capacities," and that is why "The most important thing for us is to give young people an opportunity to master a certain specialty, to provide them with a reliable start in life". (Islom Karimov, Ideology - the Uniting Principle of Notion, Society and State. p25)

As such, it is potentially an instrument of order and clarity. A neatly arranged letter will certainly make a better impression on the reader, thus good letters make good business partners.

\section{THEORETICAL BACKGROUND}

There are various methods of teaching English. Teaching a foreign language, it is necessary to pay attention to new ways to stimulate the speech of students. Much time has passed since the study of a foreign language was reduced to the passive learning of new words and expressions. And although the world has long known a huge number of approaches to the study of a foreign language and methods, a real revolutionary change in the methods of teaching English in our country occurred only in the 20th century.

The first we understood the word of meaning - method. Method - is a procedure or process for attaining an object: such as 1)a systematic procedure, technique, or mode of inquiry employed by or proper to a particular discipline or art: 2) a systematic plan followed in presenting material for instruction (https://www.macmillandictionary.com/)

All the points mentioned in previous described methods are undergoing further development in contemporary Methods abroad. There are many Methods of language teaching and a considerable amount of controversy as to the best way of foreign languages teaching abroad at present. However it is possible to group them into(1) traditional Methods which have truer origin in the grammar' translation method, and (2) audio--lingual methods which are considered to be a further development of the direct method line.

\section{TRADITIONAL LANGUAGE TEACHING}

The Grammar Translation Method, the Direct Method, and the Audio-lingual Method have been included not to give you a history of language teaching, but because they still strongly influence English instruction in many parts of the world. You will doubtless come across educationalists, now in decisionmaking positions, who have successfully learned English using one of these approaches. And their thinking on language learning is likely to be influenced by their experience. Belittling these approaches as counter-communicative or out of date may arouse their suspicion of your abilities as a teacher and may 
diminish your ability to eventually bring about change. Those of you teaching English as a secondary project may find that your older students want to use the approach they knew at school. Dismissing this attachment will not help you develop the productive relationship you want to establish with your adult students. A fundamental principle in teaching is moving from the known to the unknown. In this case, it means taking into account your students' previous experience and using some of the activities from methodologies they feel comfortable with, at least in the initial stages.

Many countries have limited funds for buying textbooks. Consequently you may find yourself working from a syllabus based on a twenty-five year old textbook which reflects only one approach. As newcomers your role is a delicate one. On the one hand, you do not want to offend with your criticisms, but on the other, you do not want to lose sight of your goal to transfer to your colleagues your technical skills and your innovative ideas. A good strategy to follow in the opening stages of your service is to be seen as covering the syllabus? using some of the activities from the prescribed methodology. Once you have established with your colleagues and students that you respect the traditions and good points of the system, you may he more successful in winning their confidence and in bringing about changes which lead to the use of other more effective teaching methods.

\section{GRAMMAR TRANSLATION METHOD}

The Grammar Translation Method looks upon language learning as an intellectual activity. Until twenty years ago, this method was commonly used in Europe to teach Latin in schools. Those countries which were closely associated with Britain or France sometimes still bear the traces of this association in the use of modified forms of Grammar Translation in language classrooms.

Distinguishing Features

In a typical Grammar Translation class the main focus is on reading and writing, with little attention being given to speaking or listening. The central text for each lesson is literary. Passages are selected from authors such as Mark Twain, George Orwell, Charles Dickens, or modern writers such as Chinua Achebe and V.S. Naipaul. These passages are read and then comprehension questions are asked and answered, first orally, then in writing. Grammar is taught deductively, through presentation and study of the rules, followed by practice through translations and exercises. Vocabulary selection is based on the reading text used. Words are taught through bilingual lists and memorization. Students are often asked to write the new words in a sentence.

Many of your students will he used to and may expect Grammar Translation activities. Memorization particularly may be considered a valued teaching tool, especially in societies where oral traditions are strong, or where periods of study in Koranic or Buddhist schools are the norm. In the United States, where the emphasis is placed on understanding concepts rather than memorizing texts, the role of memorization tends to be downgraded. However memorization does not exclude understanding, and as a teacher of languages it behooves you to play to your students' strengths. If the syllabus followed in your school includes literary texts and you have presented a poem, explored its ideas and are satisfied that your students understand them, then asking your students to learn the poem is a good way to reinforce learning and one that your students will be used to.

Your students may also be used to the style of teacher-student interaction generated by the Grammar Translation Method. In this method the teacher initiates interaction and there are seldom any student-to-student exchanges. The role of the teacher is a traditionally authoritarian one and the role of the student is to obey. Sudden changes to this dynamic can result in near chaos, so any alteration you want to make should be carried out cautiously. You may want to ask your supervisor if you can sit in on a few lessons given by your colleagues. Observing other teachers can give you an idea of the sort of studentteacher relationship which exists in your school and can give you the parameters of a model to follow.

\section{DIRECT METHOD}

The Direct Method developed in the nineteenth century as educationalists attempted to build a language learning methodology around their observations of child language learning. These educationalists argued that a foreign language could be taught without translation or use of the learner's native tongue. The Direct Method therefore insists on thinking and communicating directly in the target language and does not allow translation. The Berlitz School of Languages is the best known proponent of 
this method. The four language skills are taught from the beginning, but a special emphasis is placed on speaking. Classes often start with the reading aloud of a specially graded text which introduces the lesson's vocabulary and grammatical structure. Practice follows with exercises such as guided conversation, where the teacher asks questions on the text and the students answer using full sentences. Students will then ask each other similar questions. Other practice exercises include filling-in-the-blanks, dictation, controlled composition or listening comprehension exercises. Grammar is taught inductively, that is to say, language patterns are presented and practiced, but the rules are not explicitly given. The Direct Method teacher uses mime, demonstration, realia, and visual aids to help students understand grammar and vocabulary.

The "No Translation" rule can become an issue. Teachers complain that it is sometimes time consuming to mime vocabulary, when a simple translation would do. And some words are difficult to mime. Students become frustrated when some members of the class do not understand the teacher's explanations and when the whole class is held up until the meaning becomes clear to all.

While monitoring carefully the amount of your students' native language you use in class, you should use your common sense in this question of translation. If you judge that your students are not getting the point, or the meaning of a particular word, if you think that your lesson is straying from its objectives, and if you know the word in your students' language, then give a translation and get on with your lesson.

Many of the textbooks based on the Direct Method, most of which are by now quite dated, were written for Western school children. This can be problematic since the method is heavily dependent on the text, and the texts are not guaranteed to be culturally accessible. A textbook used in Francophone Africa describes children having cornflakes for breakfast, putting on their Wellington boots because it is raining, and catching a doubledecker bus to go to school. It is not difficult to transfer this lesson into a cultural context that your students will understand, but it is an additional barrier for your students to overcome. And your role in this process will be to provide the necessary cultural translation.

\section{AUDIO-LINGUAL METHOD (ALM)}

During the Second World War, army programs were set up to teach American military personnel languages such as German, French, Japanese and Tagalog. Strong emphasis was placed on aural oral training. The Audio-lingual Method developed from these programs. This method was also influenced by behavioral psychologists who believed that foreign language learning is basically a process of mechanical habit formation. In the Audio-lingual Method, skills are taught in the natural order of acquisition: listening, speaking, reading and writing. Audio-lingual classes begin with a dialogue which introduces the lesson's sentence patterns. The students memorize this dialogue, then practice grammar patterns in drills such as listen and repeat, substitution, chain, and transformation. Accuracy in pronunciation is emphasized and fostered through minimal pair drills where students learn to differentiate between sounds such as the vowels in "ship" and "sheep," "hit" and "heat," and "bit" and "beat." Lessons are sequenced according to grammatical complexity. Translation, considered to cause interference from the mother tongue, is not allowed. Learning is tightly controlled by the teacher, who follows the text closely.

Many of your students will be familiar with the type of activities described above. For most Americans variety and change is an essential part of their learning experience. Therefore, you may sometimes find yourself amazed by your students' stamina and capacity to repeat drills in mantra like fashion seemingly for hours at a time. To ensure that mindless chanting does not take over, you may wish to emphasize some of the speed and competitiveness promoted by the Audio-lingual Method. Some of the games referred to in Chapter Four will help your students focus on speedy comprehension, and a judicious use of group work with meaningful tasks will oblige your students to demonstrate that they are thinking about what they are saying.

Interactive learning is changing the usual forms of providing educational material on dialogue, which are based on interaction and mutual understanding. We can note the following methodological features of the organization of interactive learning: the use of problem situations and statements, the creation of appropriate dialogs, the organization of the learning space, the motivational support of joint activities, the observance of the rules of educational cooperation, the use of communicative methods and techniques, the optimization of the system for evaluating processes and results of joint activities, development introspection. and self-control of individual and group activities. At present, foreign languages should be taught in the educational process, foreign languages should be taught and communication taught.

Interactive teaching in foreign language classes 
- the development of proper thinking, the use of one's own opinions, the development of creative relationships, the perception and colloquial medium, the development of correct speech, independent understanding of the material, clear and correct broadcasting;

- development of the ability to inspire thoughts and patterns of behavior, upholding one's own opinions, creating situations of discussion, clash of opinions; Interactive technologies actively stimulate the activity of thinking aimed at overcoming contradictions and misunderstandings.

As part of a foreign language lesson, teachers use the following interactive methods and techniques:

$>$ work in small groups, in pairs, rotational threes, "two, four, together";

$>$ carousel method / "ideological" carousel;

$>$ an aquarium; - brainstorming / brainstorming / brainstorming;

$>$ "openwork saw"

$>$ Brownian motion;

$>$ "decision tree";

$>$ method of compiling a mental (intellectual) map;

$>$ conferences discussions; - role / business games;

$>$ debate.

This list can be replenished, because each teacher is able to come up with and introduce into the educational process effective techniques and methods for organizing the speech interaction of students in a foreign language lesson. I use many of these techniques in my lessons.

"Carousel" is an interactive method of work, in the process of which two rings are formed: internal and external. The inner ring is formed by the students sitting motionless, and in the outer ring the students change every 30 seconds. Thus, they manage to speak several topics in a few minutes and try to convince the interlocutor of their correctness. Using this method allows you to effectively practice etiquette dialogs. The implementation of the "ideological carousel" technique involves the following algorithm of work:

1. Each member of the micro group (4-5 people) is given a blank sheet of paper and everyone is asked the same question. Without a verbal exchange of views, all participants write spontaneous wordings of answers to it on their sheets of paper.

2. Leaflets with time-lapse recordings are transmitted in a clockwise circle to neighbors in a micro group. Upon receipt of a sheet of entries, each participant must make a new entry without repeating the existing ones. The work ends when everyone returns his sheet. At this stage, the records are not analyzed or evaluated.

3. In micro groups, there is a discussion of the responses formulated by the participants, suggestions and allocation to the final list of the most important, relevant ones.

4. Exchange of the results of the developments of micro groups. All micro groups offer their wordings from the final list in turn. If the wording does not meet the objections of other groups, it is included in the final general list.

Reception "Aquarium" is a "performance", where viewers act as observers, experts, critics and analysts. Several students act out the situation in a circle, while others observe and analyze it. So, for example, studying the topic "How do Teens Express Their Individuality?" In grade 10, you can offer an "aquarium dialogue": the text of the dialogue can be any, for example, a conversation of representatives of several youth subcultures. The task of the actors is to convey the relevant features, features of a particular subculture, and the task of the audience is to determine which subculture the speakers presented. Roles can be offered either by the teacher himself, naturally, secretly from the audience, or the students themselves can choose the subculture whose views they share and want to present / discuss.

The "brainstorming" method (brainstorming, "brainstorming") is an operational method for solving a problem based on stimulating creative activity. The participants in the discussion are invited to express as many possible solutions as possible; from the total number of ideas expressed, the most successful ones can be used in practice. The options for using this method in a foreign language lesson may be the following: 
1. Start the lesson with a brainstorming session as a voice charge - Warming Up, asking students questions: What are your associations with ...? What do you associate with ...? What immediately comes into your mind when you hear ...?

2. Invite students to relax, tune in to the topic of reflection, take pens and write down the thoughts that come to their mind on a particular topic / problem.

3. Brainstorming as an interactive technique for organizing a group discussion at the pretext stage. Using this technique involves a step-by-step implementation. Step 1 - warm up (lasts 3 minutes). For several lessons, the theme "Is It Easy To Be Young?" Has been explored. The teacher offers to conduct brainstorming with the participation of all students in the group and to name as many ideas as possible that they associate with this topic. A mental map (cluster) is drawn up, and "Teenage Problems" is among the ideas. Step 2 - uniting students in mini-groups. Step 3 - work in mini-groups for 7 minutes. The teacher clearly sets out the problem or issue to be resolved. So, for example, one can propose to hold a brainstorming in mini-groups on the text problem, which is to be read by the students of "Young People - Old Problems". The task of the students is to express and write down as many ideas as possible (even the most absurd), and then after reading the text to conclude what problems are inherent to adolescents around the world, and which concern adolescents.

\section{CONCLUSION}

To sum up, before choosing teaching methods, a foreign language teacher should be guided by those specific tasks of the educational process, the results of which meet the requirements for the formation of specific practical skills of students. Practical exercises that are built on the basis of interactive technologies make it possible to effectively study educational material. Thus, the conditions are created for learning a foreign language at a qualitatively new and high level and for using these formed skills in practice.

\section{REFERENCES}

1. Current trends in the development and teaching of the four language skills. Edited by Esther Uso.-Juan, Alicia Martı.nez-Flor. - Berlin, 2006

2. Pshenichnova, E.N.Teaching foreign students to Russian professionally-oriented business communication. PhD thesis (Education), Moscow. 2007

3. Gagarina, N.V.Methodical system of training reproductive and productive speaking based on the text types for specific purposes. PhD thesis (Education), Tula. 2010

4. Hampden-Turner, Ch., Trompenaars, F.Building Cross-Cultural Competence.USA: Yale University Press. 2000

5. Hulstijn, J.H. The Use Of Computer Technology In Experimental Studies Of Second Language Acquisition: A Survey Of Some Techniques And Some Ongoing Studies. Language Learning \& Technology. Vol. 3, No.2, 2000

6. Shaturnaya, E.A. Methods of teaching foreign language professional discourse by means of training-speech situations and roleplaying. PhD thesis (Education), Tambov. 2009 